\title{
Estimated number of women likely to benefit trom bone mineral density measurement in France
}

\author{
Nassira Amamra ${ }^{\mathrm{a}}$, Claudine Berr ${ }^{\mathrm{b}}$, Françoise Clavel-Chapelon ${ }^{\mathrm{c}}$, Cécile Delcourt ${ }^{\mathrm{d}}$, Pierre D. \\ Delmase, Francis Derriennic ${ }^{\mathrm{f}}$, Pierre Ducimetières, Marcel Goldbergh, Luc Letenneur ${ }^{\mathrm{i}}$, \\ Muriel Rabilloud ${ }^{\mathrm{j}}$, Pierre-Jean Meunier ${ }^{\mathrm{k}}$ and Anne-Marie Schott ${ }^{*}$, a
}

${ }^{a}$ Département d'Information Médicale des Hospices Civils de Lyon, 162 avenue Lacassagne, 69003, Lyon, France

${ }^{b}$ GH Pitié-Salepétrière, unité Inserm U 360, 75651, Paris cedex 13, France

${ }^{c}$ Institut Gustave Roussy, unité Inserm XR 521, 94805, Villejuif cedex, France

${ }^{d}$ Unité Inserm U 500, 39, avenue Charles Flahault, 34093, Montpellier cedex 5, France

${ }^{e}$ Hôpital E. Herriot, unité Inserm U 403, pavillon F, 69003, Lyon, France

${ }^{f}$ Unité Inserm U170, 16, avenue Paul Vaillant-Couturier, 94807, Villejuif cedex, France

${ }^{g}$ Hôpital Paul Brousse, unité Inserm U 258, 94807, Villejuif cedex, France

${ }^{h}$ Hôpital National St. Maurice, unité Inserm U 88, 94415, St. Maurice cedex, France

${ }^{i}$ Université Victor Segalen, unité Inserm U 330, 33076, Bordeaux cedex, France

j Service de biostatistiques, 162, avenue Lacassagne, 69003, Lyon, France

k Faculté de médecine, R.T.H. Laënnec rue Guillaume Paradin, 69372, Lyon cedex 8, France

\begin{abstract}
Objectives. - To determine the number of women in France at least 50 years of age with risk factors for osteoporosis likely to lead to bone mineral density measurement, an investigation reimbursed by the French national health insurance system in patients at risk for osteoporosis. The study was commissioned by the French health authorities.

Materials and methods. - Risk factors for osteoporosis were defined as recommended by the French Agency for Accreditation and Evaluation in Health (ANAES) in 2001. The study data were from nine cohort studies done in France and from the National Health Insurance Agency for the Rhône-Alpes region of France. Risk factor prevalences in France were standardized by extrapolation according to the age distribution in France.

Results. - Overall, data were collected in 123986 women aged 50 years or older. From these data, risk factor estimates were as follows: menopause before 40 years of age, 1.5 million women; body mass index (BMI) lower than $19 \mathrm{~kg} / \mathrm{m}^{2}$, nearly 700000 ; history of fracture, more than 2 million; history of femoral neck fracture in the mother, more than 1 million; history of health problems potentially responsible for osteoporosis, 400 000; and history of long-term glucocorticoid therapy, 612 000. In all, 3186318 (30\%) women were estimated to have at least one risk factor and 785512 (7.5\%) at least two risk factors.

Conclusions. - Although our study sample was not representative of the population residing in France, the large sample size and diversity of data sources support the validity of our estimate of the prevalence of risk factors for osteoporosis in postmenopausal women living in France.
\end{abstract}

Author Keywords: Osteoporosis; Prevalence; Risk factors; Absorptiometry; Bone mineral density; Menopause

\section{Introduction}

The prevalence of osteoporosis is rising, most notably in postmenopausal women. Fractures caused by trivial trauma are the main clinical manifestations. The vertebras and distal forearm are the most commonly affected sites, whereas fractures of the proximal femur are the most severe ${ }^{1,2,3}$ and 4 . In 1994 , the World Health Organization defined osteoporosis as an unacceptable risk of fracture detected on the basis of a bone mineral density (BMD) $T$-score value by absorptiometry lower than -2.5 standard deviation (S.D.). The $T$-score reflects the difference, in S.D., between the BMD in the patient and the mean BMD in a reference population of young healthy women examined when their bone mass was at its peak. Several

\footnotetext{
* anne-marie.schott-pethelaz@chu-lyon.fr
} 
recommendations about selecting patients for BMD measurement have been issued, in particular by the Osteoporosis Research and Information Group (Groupe de Recherche et d'Information sur les Ostéoporoses, GRIO) and the European Foundation against Osteoporosis (EFO) $)^{5,6,7,8,9,10,11,12}$ and 13 . Compliance with these recommendations has not yet been evaluated. In 2001, at the request of the Ministry of Health and national health insurance system, the French Agency for Accreditation and Evaluation in Health (ANAES) developed a tentative definition of women at high risk for osteoporosis ${ }^{14}$. Absorptiometry was not reimbursed by the national health insurance system at the time. Yet, this investigation may be extremely helpful in women at high risk for osteoporosis, and many risk factors for osteoporosis have been identified.

To obtain recognition of absorptiometry as a medical procedure warranting reimbursement by the universal health insurance system, the French Agency for Health asked us to estimate the number of women in France who were at risk for osteoporosis according to the ANAES guidelines. These women constitute the population likely to benefit from absorptiometry, that is, the population for which absorptiometry should be reimbursed by the national health insurance system.

The objective of this study was to estimate the prevalence in France of women with risk factors for osteoporosis listed in the ANAES guidelines. To achieve this objective, we used available databases.

\section{Materials and methods}

\section{Materials}

We looked for computerized databases of cohort studies in women older than 50 years living in France $^{15,16,17,18,19,2021,22 \text { and } 23}$ at the following institutions: National Institute for Health Statistics and Research (Institut National de la Santé et de la Recherche Médicale, INSERM, web site <inserm.fr>), National Institute for Statistics and Economic Evaluations (Institut National des Statistiques et des Études Économiques, INSEE, 1990 census), National Health Insurance Agency for the Rhônes-Alpes region, and the national utility company (Électricité de France, EDF). The cohort studies identified by our search are listed in appendix A. We excluded four studies for one or more of the following reasons: major selection bias likely to affect the validity of our estimate, population younger than 50 years, or data not relevant to the risk factors studied in our work. For instance, in the study "second cancer after breast cancer", the population with a history of breast cancer was not representative of the general population in terms of the risk factors investigated in our study. Possible sources of bias included differences in menopausal status and in bone tissue status. The GAPIC study investigated coronary heart disease and other cardiovascular disorders. As a result, males predominated. In addition, the restrictive selection criteria produced a population that differed markedly from the general population. The study "health effects of exposure to water side products" was conducted in selected groups such as underground miners and swimmers. Most of the study participants were males, which was not relevant to our objective. Finally, in the study "benign breast disease and breast cancer risk", the mean age of the women was too young to be relevant to our study.

The risk factors investigated in our study were those listed in the 2001 ANAES guidelines on patient selection for absorptiometry ${ }^{1}$. These guidelines deal primarily with the tools used to diagnose osteoporosis in postmenopausal women and in male and female adults on glucocorticoid therapy. One of their objectives is to indicate when investigations to evaluate the risk of osteoporotic fractures are appropriate. In brief, absorptiometry is recommended in postmenopausal women with any of the following: one or more vertebral fractures discovered on radiographs in the absence of a tumor or major trauma; history of peripheral fracture in the absence of major trauma (not counting fractures of the skull, toes, fingers, and cervical spine); and documented history of conditions potentially responsible for osteoporosis (e.g. prolonged hypogonadism, active untreated hyperthyroidism, hypercorticism, and primary hyperparathyroidism $)^{1}$. In addition, absorptiometry can be recommended to postmenopausal women with one or more of the following risk factors: history of vertebral or femoral neck fracture in the absence of major trauma in a first-degree relative, body mass index (BMI) lower than $19 \mathrm{~kg} / \mathrm{m}^{2}$, menopause before 40 years of age regardless of the cause or iatrogenic menopause, and history of glucocorticoid therapy for longer than 3 months in a dose of at least $7.5 \mathrm{mg}$ prednisone-equivalent per day ${ }^{1}$. Absorptiometry is not recommended in postmenopausal women taking hormone replacement therapy in a dosage effective in preventing osteoporosis and under appropriate medical supervision ${ }^{1}$.

We also collected information on several additional factors (such as history of fracture after 50 years of age or after the menopause) relevant to recommendations issued by other evaluation agencies or likely to have a major influence on our estimate of at risk women. 


\section{Risk factors used for our estimate}

A review of the ANAES recommendations and of the cohort study data indicated that the main risk factors for osteoporosis in women older than 50 years were menopause before 40 years of age, history of fracture after 50 years of age, history of fracture in the mother, BMI lower than $19 \mathrm{~kg} / \mathrm{m}^{2}$, history of conditions potentially responsible for osteoporosis, and history of glucocorticoid therapy for at least 3 months in a daily dosage of at least $7.5 \mathrm{mg}$. To evaluate the heterogeneity of the data used for our estimate, we asked the main investigators of the cohort studies to supply us with the exact wording of the items in their study questionnaires. In the database maintained by the Rhônes-Alpes Insurance Agency, we selected data on women who were older than 50 years, resided in the Rhône-Alpes area, were covered by the National Health Insurance Agency for salaried workers, and had obtained reimbursement for at least two prescriptions of glucocorticoids written on different dates in the course of 2000.

The EPIDOS cohort study collected data on five risk factors: menopause before 40 years of age, BMI lower than $19 \mathrm{~kg} / \mathrm{m}^{2}$, history of fracture, fracture in the mother, and history of glucocorticoid therapy. The PAQUID and EVA cohort studies recorded only menopause before 40 years of age and BMI lower than $19 \mathrm{~kg} / \mathrm{m}^{2}$. Risk factors recorded in the OFELY study were menopause before 40 years of age or iatrogenic menopause, BMI lower than $<19 \mathrm{~kg} / \mathrm{m}^{2}$, history of fracture after 50 years of age (not due to a tumor or major trauma), hip fracture in the mother, and history of glucocorticoid therapy or hyperthyroidism. In the ESTEV 95 study, four risk factors were investigated: menopause before 40 years of age, BMI lower than $19 \mathrm{~kg} / \mathrm{m}^{2}$, history of fracture after 50 years of age, and history of conditions potentially responsible for osteoporosis. The E3N study recorded menopause before 40 years of age, BMI lower than $19 \mathrm{~kg} / \mathrm{m}^{2}$, history of fracture after 50 years of age, and history of hip fracture in the mother. Three factors were recorded in the GAZEL study: menopause before 40 years of age, BMI lower than $19 \mathrm{~kg} / \mathrm{m}^{2}$, and fracture after 50 years of age. Finally, the MONICA study investigated only two risk factors, menopause before 40 years of age and BMI lower than $19 \mathrm{~kg} / \mathrm{m}^{2}$.

We sent a questionnaire to the investigators of each of the nine cohort studies. Our first analysis of the responses was done study-by-study. Then, we analyzed the pooled data from the nine studies, by age group and risk factor. Finally, we standardized the results to obtain estimates of risk factor prevalences. Because the age distribution of our study sample differed from that of the overall population of women older than 50 years living in France, we selected the direct standardization method to correct our results. Furthermore, the data on glucocorticoid therapy in the nine cohort studies were also standardized on the age distribution in the population living in the Rhône-Alpes area (1999 INSEE census) to allow a comparison between the prevalence in the cohort studies and in the Rhône-Alpes Insurance Agency database.

\section{Results}

Eleven cohort studies met our eligibility criteria, and the main investigators for nine of these studies completed our study questionnaire. Table 1 describes the objectives of each study, the population, and the follow-up dates. In all, the nine cohorts included 123986 women older than 50 years.

For each of the four most often studied risk factors (menopause before 40 years of age, history of fracture, history of fracture in the mother, and BMI lower than $19 \mathrm{~kg} / \mathrm{m}^{2}$ ), Table 2, Table 3 and Table 4 report the prevalences per age group and the number of women for whom data were available.

\section{Menopause before 40 years of age}

The prevalence of menopause before 40 years of age is shown in Table 2. This risk factor was investigated in six of the nine cohort studies. For each study, the table shows the age groups and sample size (first column for each study). Wide variations in prevalence were seen across studies, from $5.5 \%$ in the PAQUID cohort to $23.4 \%$ in the EPIDOS cohort. The figures in the last column of the table are strongly influenced not only by age but also by the number of studies providing data for each age group and by their relative contribution to the total number of women in each age group.

The mean overall prevalence of menopause before 40 years of age was $15 \%$. The E3N cohort had the largest influence on the prevalence in the 50-65-year age group and the EPIDOS cohort on the prevalence in the 75 years or older age group. In the 65-74-year age group, the sample size was far smaller (500600 women) and the data came only from two studies, the OFELY cohort and, above all, the PAQUID cohort (90\% of data for the 65-69-year group and 82\% for the 70-74-year group). Within each age group, marked differences were noted across cohorts. In the 55-59-year group, for instance, the prevalence of menopause before 40 years ranged from 12\% in OFELY and 13\% in E3N to 24\% in ESTEV95. In the 80- 
84-year group, the lowest prevalence was 5.4\% in PAQUID and the highest was 22\% in EPIDOS. Thus major prevalence differences occurred across the nine studies both overall and within age groups. In the PAQUID cohort, the prevalence of menopause before 40 years of age was substantially lower than in the other cohorts, in all age groups. In contrast, in each age group, the prevalence of a BMI lower than $19 \mathrm{~kg} / \mathrm{m}^{2}$ in PAQUID was greater than in the other cohorts (Table 3).

Table 1. Main characteristics of the nine cohort studies used to estimate the prevalence of risk factors for osteoporosis in women older than 50 years living in France

\begin{tabular}{|c|c|c|c|c|}
\hline Study & Priniry focus of the study & Sample size & Sample source & $\begin{array}{l}\text { Recnuifment and dafa cellection } \\
\text { dafes }\end{array}$ \\
\hline EPIDOS & Osfecporesis & 7517 & $\begin{array}{l}\text { Voter roskers (Mempellier, } \\
\text { Toulouse, Lyon, Pais, } \\
\text { Anniens) }\end{array}$ & $1 / 92-1 / 94$ \\
\hline ESTEV9S & Healsh, work, and aging & 7425 & $\begin{array}{l}\text { Employees followed } \\
\text { by } 380 \text { occupational } \\
\text { physicians (seven regions) }\end{array}$ & 19901995 \\
\hline EVA & $\begin{array}{l}\text { Hemene replacement ther- } \\
\text { apy }\end{array}$ & 469 & $\begin{array}{l}\text { Volunieers from voter nos- } \\
\text { ters }\end{array}$ & $6 / 1991-6 / 1993$ \\
\hline E3N & $\begin{array}{l}\text { Risk factors for cancer and } \\
\text { chronic disense }\end{array}$ & 9899 & $\begin{array}{l}\text { Feniale members of the } \\
\text { MGEN }\end{array}$ & 1990 \\
\hline GAZEL & $\begin{array}{l}\text { Linderatanding of "indiea- } \\
\text { vions" for hommene replace- } \\
\text { ment therspy arsd poor } \\
\text { sompliance with this treat } \\
\text { nemt }\end{array}$ & 3157 & $\begin{array}{l}\text { Fench public ufilify com- } \\
\text { pany }\end{array}$ & 1989 \\
\hline MONICA & $\begin{array}{l}\text { Candiovascular disease } \\
\text { (morbidify, montality, risk } \\
\text { fuctors) }\end{array}$ & 1730 & $\begin{array}{l}\text { Three registries (Stras- } \\
\text { bourg, Toulowse, and Lille) }\end{array}$ & 1985 \\
\hline ORELY & Ostecpcresis & 1039 & $\begin{array}{l}\text { Volunteers annong nem- } \\
\text { bens of the MGEN }\end{array}$ & 1992 \\
\hline PAQUID & $\begin{array}{l}\text { Brain aging and loss of } \\
\text { self-sufficiency in individu- } \\
\text { als }>65 \text { yens living af home }\end{array}$ & 2200 & $\begin{array}{l}75 \text { counties in Glronde and } \\
\text { Derdogne (two districts in } \\
\text { swoth-westem Fronce) }\end{array}$ & $1988-1990$ \\
\hline POLA & $\begin{array}{l}\text { Catanact and age related } \\
\text { nacular degenciation frisk } \\
\text { facters) }\end{array}$ & 1451 & $\begin{array}{l}\text { Sete (city in southem } \\
\text { France) }\end{array}$ & $6 / 1995-7 / 1997$ \\
\hline
\end{tabular}

Table 2. Menopause before 40 years of age: prevalence among women older than $\mathbf{5 0}$ years of age included in six cohort studies

\begin{tabular}{|c|c|c|c|c|c|c|c|c|c|c|c|c|c|}
\hline Age greup (years) & Name of the study & & & & & & & & & & & & Peced data (se lotal) \\
\hline & EPIDOS & & ESTEVOS & & E3N & & MONICA & & CFELY & & PAQUD & & \\
\hline & Towal sample sizes & $\%$ & Tetal sample size & $\%$ & Total sample size & $\%$ & Total sample size & $\%$ & Tonal sample size & $\%$ & Total sample size & $\%$ & \\
\hline $50-54$ & & & 1995 & 16.1 & 15758 & 12.75 & 374 & 11.8 & 127 & 10.2 & & & 13.1 \\
\hline $55-59$ & - & - & 1668 & 23.6 & 11820 & 12.97 & 298 & 17.1 & 202 & 11.9 & $=$ & - & 14.3 \\
\hline $60-64$ & - & - & - & - & 7273 & 14,71 & 326 & 21,2 & 100 & 12,0 & - & - & 14,9 \\
\hline $65-69$ & - & - & - & - & - & - & - & - & 61 & 11.5 & 601 & 5.2 & 5.2 \\
\hline $70-74$ & - & - & - & - & - & - & - & - & 89 & 16.9 & 436 & 6.9 & 69 \\
\hline $75-79$ & 3880 & 23.5 & - & - & - & - & - & - & 46 & 19.6 & 549 & 6.0 & 21.3 \\
\hline $80-84$ & 2611 & 221 & - & - & - & - & - & - & 33 & 12.1 & 333 & 5,4 & 20,2 \\
\hline $85-89$ & 834 & 25.9 & - & - & - & - & - & - & & & 205 & 3.9 & 21.6 \\
\hline 290 & 133 & 29.3 & - & - & - & - & - & - & & & 76 & 2,6 & 30,8 \\
\hline Tomal & 7458 & 23.4 & 3663 & 19.5 & $34 \$ 51$ & 13.2 & 903 & 16,9 & $66 \%$ & 12.6 & 2200 & 5.5 & 15.0 \\
\hline
\end{tabular}

Table 3. BMI lower than $19 \mathrm{~kg} / \mathrm{m}^{2}$ : prevalence among women older than 50 years of age included in seven cohort studies

\begin{tabular}{|c|c|c|c|c|c|c|c|c|c|c|c|c|c|c|c|}
\hline \multirow{3}{*}{ Age group (yeans) } & \multirow{2}{*}{\multicolumn{2}{|c|}{$\begin{array}{l}\text { Nane of the study } \\
\text { gPIDOs }\end{array}$}} & \multirow{2}{*}{\multicolumn{2}{|c|}{ FSTRYOS }} & & \multirow{2}{*}{\multicolumn{2}{|c|}{ MONICA }} & \multirow{2}{*}{\multicolumn{2}{|c|}{ OFFIY }} & \multirow{2}{*}{\multicolumn{2}{|c|}{ PAQIתI }} & & \multirow[t]{3}{*}{ 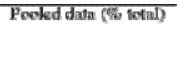 } \\
\hline & & & & & E3N & & & & & & & & POLA & & \\
\hline & Total sample size & \% & Total sample size & $\%$ & Total sample size & $\%$ & Total sample size & $\%$ & Toxal sample size & $\%$ & Total sample size & $\%$ & Total sample size & \% & \\
\hline $50-54$ & $=$ & $=$ & 1995 & 2.3 & 15758 & 9.1 & 279 & 3.2 & 127 & 4.7 & $=$ & $=$ & $=$ & $=$ & 82 \\
\hline $55-59$ & - & - & 1668 & 2,2 & 11520 & 9.1 & 298 & 1.0 & 202 & 4,0 & - & - & $=$ & $=$ & 80 \\
\hline $60-64$ & - & - & - & - & 7273 & 9.5 & 326 & 15 & 100 & 4.0 & - & - & 333 & 3.3 & 8.9 \\
\hline 65-69 & - & - & - & - & - & - & - & - & 61 & 6.6 & 601 & 3,7 & 370 & 1.9 & 32 \\
\hline $70-74$ & - & - & - & - & - & - & - & - & 89 & 1.1 & 436 & 7.6 & 357 & 2 & 4.7 \\
\hline $75-79$ & 3850 & 3.8 & - & - & - & - & - & - & 46 & 2.2 & 549 & 7.7 & 220 & 4,1 & 4,3 \\
\hline so-s4 & 2611 & 4,2 & - & - & - & - & - & 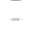 & 33 & 3,0 & 333 & 9.6 & 112 & 2,7 & 4.7 \\
\hline $85-89$ & 834 & 5.5 & $\overline{-}$ & - & - & $=$ & - & - & 33 & 3,0 & 305 & 11,7 & 47 & 0 & 6.4 \\
\hline 290 & 133 & 13.5 & - & - & - & - & - & - & & & 76 & 21,1 & 7 & 0 & 15.8 \\
\hline Tefal & $745 s$ & 4.3 & 3663 & 2.2 & 34551 & 9.2 & 903 & 1.9 & 669 & 3.7 & 2200 & 7.7 & 1446 & 2.6 & $7.5 * 6$ \\
\hline
\end{tabular}


Table 4. History of fracture: prevalence among women older than $\mathbf{5 0}$ years of age included in four cohort studies

\begin{tabular}{|c|c|c|c|c|c|c|c|c|c|}
\hline \multirow[t]{3}{*}{ Age group (years) } & \multicolumn{8}{|l|}{ Rame of the sfudy } & \multirow[t]{3}{*}{ Fooled data (\% tofal) } \\
\hline & E3N ${ }^{2}$ & & EPDOS 2 & & ESTEV95: & & OFELY $Y^{\circ}$ & & \\
\hline & Total sample size & 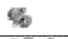 & Tofal sample sfre & $\mathscr{B}$ & Total sample stze & \% & Total sample shes & $\mathscr{W}$ & \\
\hline $50-54$ & 15758 & 10.6 & $=$ & $=$ & 1995 & 2.1 & 127 & 24 & 9.7 \\
\hline $55-59$ & 11580 & 16.0 & - & - & 1668 & 4,4 & 202 & L.0 & 14.5 \\
\hline $60-64$ & 7272 & 22.2 & - & - & - & $=$ & 100 & 5.0 & 222 \\
\hline $65-69$ & - & - & - & - & - & - & 6] & 4.9 & 4.9 \\
\hline $70-74$ & - & - & - & - & - & - & 89 & 11.2 & 11,2 \\
\hline $75-79$ & - & - & 3850 & 36.4 & - & - & 46 & 19.6 & 36.7 \\
\hline $80-84$ & - & - & 2611 & 37.8 & - & $=$ & 33 & 303 & 38.2 \\
\hline $85-89$ & - & - & 834 & 39.1 & - & - & & & 39.1 \\
\hline 200 & - & - & 133 & 31,6 & - & - & & & 31,6 \\
\hline Total & 34851 & 14.8 & 7458 & 37,1 & 3663 & $3_{n} 1$ & 669 & 6.3 & 17.6 \\
\hline
\end{tabular}

The prevalence of women with a history of menopause before 40 years increased significantly with age in four of the six cohorts, the two exceptions being EPIDOS and PAQUID. In the PAQUID cohort, the prevalence seemed to decrease with age. Thus, we noted both an age effect and a cohort effect, which in some cases could not be separated from each other given the marked age distribution differences between the two studies, with some pairs of studies having no shared age groups.

Prevalence of a body mass index lower than $19 \mathrm{~kg} / \mathrm{m}^{2}$

As shown in Table 3, the prevalence of a BMI smaller than $19 \mathrm{~kg} / \mathrm{m}^{2}$ ranged from $1.9 \%$ in the MONICA cohort to $9.2 \%$ in the E3N cohort. The overall prevalence was higher in the PAQUID cohort (7.7\%) than in the EPIDOS cohort (4.3\%). Similar differences were found in each age group. For instance, in the 75-79-year group, 7.7\% of women in the PAQUID cohort and 3.8\% in the EPIDOS cohort had a BMI lower than $19 \mathrm{~kg} / \mathrm{m}^{2}$. These are the only two studies in which age had a significant influence. No such effect was seen in the POLA cohort, which collected data in the same age groups.

\section{History of fracture after 50 years of age}

Again, prevalence values varied widely, from 3.1\% (ESTEV95) to 37.1\% (Table 4). Prevalence increased with age in all the studies. Given the heterogeneity of the cohorts related to differences in patient selection criteria and in definitions of a history of fracture, results varied markedly even within age groups. Thus, among women aged 50-54 years, the prevalence was 2.1\% in ESTEV95 ( $n=1995), 2.4 \%$ in OFELY $(n=127)$, and $10.63 \%$ in E3N $(n=15758)$ (Table 4). Similar differences were found in the other age groups. Higher prevalences were seen in the studies that used broader definitions for a history of fracture. The increase with age within a given study was statistically significant in all the cohorts except EPIDOS.

\section{History of proximal femoral fracture in the mother}

The prevalence of a history of proximal femoral fracture in the mother (Table 5) ranged from 8.7\% (E3N) to $11.1 \%$ (OFELY). Thus, variability across studies was less marked than for other risk factors. Age did not seem to affect the prevalence of this risk factor. An age effect was seen only in the E3N cohort, which contributed $80 \%$ of the total sample for this risk factor. The overall prevalences in the E3N, EPIDOS, and OFELY cohorts were about $8.7 \%$, 9.1\%, and $11.1 \%$, respectively. In the GAZEL study, the overall prevalence was $8.8 \%$ and age group data were not available. The overall prevalence in our sample was $8.8 \%$. After standardization for the age distribution in the population of women older than 50 years living in France, the overall prevalence was 10.3\% (9.7-10.9\%) (Table 8).

\section{History of disorders potentially responsible for osteoporosis}

Five cohort studies collected the history of disorders listed by the ANAES as potentially responsible for osteoporosis (prolonged hypogonadism, active untreated hyperthyroidism, hypercorticism, and primary hyperparathyroidism). However, the definitions used for this risk factor showed substantial heterogeneity. The prevalences ranged from $3 \%$ to $7 \%$. Their validity is limited, however, by the very small sample sizes, particularly in women older than 60 years. For instance, a history of "untreated hyperthyroidism" was nearly impossible to evaluate because the four studies that investigated this factor used different definitions; prevalences were 1\% (20/2200) in PAQUID, 1.9\% (54/2917) in ESTEV95, 4.3\% (29/669) in OFELY, and 4.98\% (3322/66 710) in E3N. The prevalence in the Rhône-Alpes Health Insurance Agency database was 4.7\% (3425/72 496), which is similar to the values in the E3N and OFELY cohorts. In the GAZEL cohort, 
17.9\% of participants reported a history of prolonged amenorrhea (more than 3 months before the menopause).

Table 5. History of fracture of the proximal femur in the mother: prevalence among women older than 50 years of age included in three cohort studies

\begin{tabular}{|c|c|c|c|c|c|c|c|}
\hline \multirow[t]{3}{*}{ Age group (yeans) } & \multicolumn{4}{|l|}{ Name of the study } & \multirow{2}{*}{\multicolumn{2}{|c|}{ EPIDOS }} & \multirow[t]{2}{*}{ Pooled data (C) } \\
\hline & E3N & & OFEIY & & & & \\
\hline & Total sample size & ⿷ & Total sample size & $\%$ & Total sample size & s & \\
\hline $50-54$ & 15758 & 7.5 & 127 & 63 & $=$ & $=$ & 7.5 \\
\hline $55-59$ & 11820 & 8,9 & 202 & 15,3 & $=$ & $=$ & 8.9 \\
\hline $60-64$ & 7273 & 107 & 100 & 8.0 & - & - & 10.7 \\
\hline $65-60$ & - & - & 61 & 13,1 & - & - & 13,1 \\
\hline $70-74$ & - & - & 89 & 14.6 & $=$ & $=$ & 14.6 \\
\hline $75-80$ & - & - & 46 & 6,5 & 3850 & 9.1 & 9.1 \\
\hline $80-84$ & - & - & 33 & 9.1 & 3611 & 8.8 & 8.8 \\
\hline $85-89$ & - & - & & & 834 & 9.8 & 9.8 \\
\hline 290 & - & - & & & 133 & 8.3 & 83 \\
\hline Total & $34 \$ 51$ & 8.7 & 669 & $11_{n} 1$ & 7458 & 9.1 & 8.8 \\
\hline
\end{tabular}

Table 8. Estimated numbers of women with each risk factor for osteoporosis

\begin{tabular}{|c|c|c|c|c|c|c|}
\hline Risk factor & Crude prevalence (\%) & $T(s)(\infty)^{2}$ & $95 \% \mathrm{C}$ of $F(s)(\mathrm{s})$ & $\begin{array}{l}\text { Estimated } \\
\text { wonsen " }\end{array}$ & nomber of & $\begin{array}{l}\text { 95se } \mathrm{CI} \text { of the estimated } \\
\text { number }\end{array}$ \\
\hline Menopause betore 40 years & 15 & 14,11 & $13,92-14,29$ & 1490593 & & $1470521-1509609$ \\
\hline BMT $\leq 19 \mathrm{kgh \textrm {r } ^ { 2 }}$ & 7.5 & 66 & $6.48-6.71$ & 697230 & & $684553-708851$ \\
\hline History of fiacture" & 17.6 & 19.0 & $18,47-19,41$ & 2007177 & & $1951158-2050490$ \\
\hline $\begin{array}{l}\text { Histexy of fractue in the } \\
\text { mother }\end{array}$ & 8.8 & 103 & $9.67-10.9$ & 1088101 & & $1021548-1151486$ \\
\hline $\begin{array}{l}\text { History of diseases associ- } \\
\text { afed with esfeoporosis }\end{array}$ & 4,3 & 3,8 & $3.31-4.37$ & 401435 & & $349671-461651$ \\
\hline $\begin{array}{l}\text { History of slueocenticeid } \\
\text { therapy }\end{array}$ & 6,6 & 5.79 & $5-6.58$ & 611661 & & $528305-695117$ \\
\hline
\end{tabular}

95\% CI, 95\% confidence interval.

\section{History of glucocorticoid therapy}

This factor was investigated in three cohort studies (EPIDOS, OFELY, and PAQUID), in which the overall mean prevalence was $6.6 \%$. The prevalence in the Rhône-Alpes health insurance database was $5.7 \%$. Standardization of the cohort data for the age distribution among women older than 50 years living in the Rhône-Alpes area yielded a mean prevalence of 5.7\%. Thus, we found close agreement between the cohort data and the health insurance data. The prevalence standardized for the age distribution of the population living in France was 5.8\% (5-6.6\%). The method used to collect data on glucocorticoid therapy differed across cohorts. No age effect was noted.

\section{Prevalence of one or more risk factors}

Table 6 and Table 7 report the prevalence of women with at least one or at least two risk factors in each cohort and age group. The overall prevalence of women with at least one risk factor was derived from eight studies that collected data in various age groups (Table 6). The number of risk factors studied ranged from two to six. The overall prevalence of women with at least one risk factor ranged from $12.7 \%$ in the PAQUID study to $51.7 \%$ in the EPIDOS study. Even in the same age groups, marked variations occurred across cohorts. Prevalences were highest in EPIDOS and OFELY, two studies designed to identify risk factors for osteoporosis; the lowest prevalence was in the PAQUID study, which investigated aging and loss of self-sufficiency. In the 65-69 and 70-74-year groups, the numbers of patients were small. For these reasons, the results are more difficult to interpret in these two age groups.

Table 6. Overall prevalence of women with at least one risk factor for osteoporosis among women older than 50 years of age included in eight cohort studies 


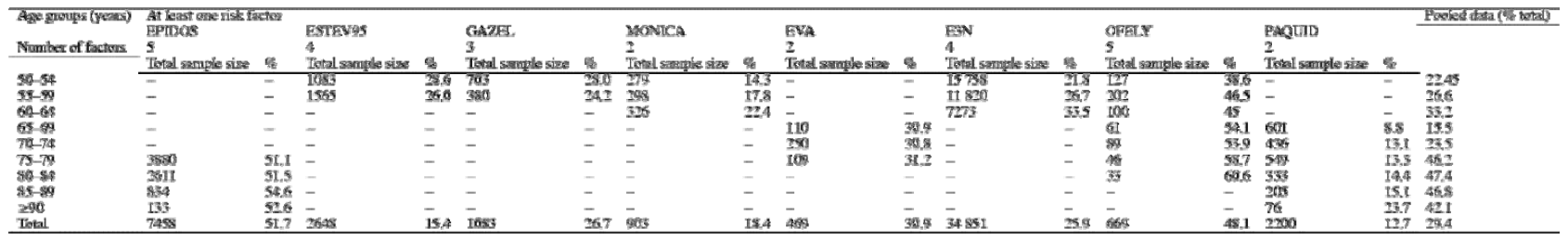

Table 7. Overall prevalence of women with at least two risk factors for osteoporosis among women older than 50 years of age included in eight cohort studies

\begin{tabular}{|c|c|c|c|c|c|c|c|c|c|c|c|c|c|c|c|c|}
\hline Ape group (yeass) & 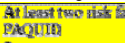 & chers & लАनग. & & мoveca & & Eva & & Fas & & OFEYY & & Еทров & & ESTRVBS & Foxhed data ("se toral) \\
\hline Nomiber of faction: & & & 3 & & 2 & a & $\frac{2}{2}$ & & & & & & & & & \\
\hline s0.-5e & Woctsanger sine & & 705 & $3 \pi$ & $z^{2 y}$ & का. & & & 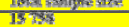 & का & 125 & प⿺辶 & & $\%$ & $-\frac{1053}{105}$ & \\
\hline 32-90 & - & - & 350 & 8.6 & 398 & $a^{3}$ & - & - & 11539 & 6.6 & 202 & s.o & - & - & t565 & 1.35 .8 \\
\hline $60-68$ & - & - & - & - & 3206 & es & - & - & 7273 & $x 2$ & 100 & 10,0 & - & - & - & -8.8 \\
\hline $65-89$ & 602 & 08 & - & - & - & - & 116 & 18 & - & - & $6 \mathrm{I}$ & 11.5 & - & - & - & $-\quad 18$ \\
\hline $72-73$ & 836 & 1,4 & - & - & - & - & 230 & 3 & - & - & 89 & 67 & - & - & - & $-\quad 32$ \\
\hline $72-79$ & 5758 & 0.4 & - & - & - & - & 103 & is & - & - & 40 & $21, ?$ & 3ssat & 17.1 & - & $-\quad 14.8$ \\
\hline 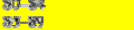 & $\frac{356}{305}$ & 10.5 & - & $=$ & $=$ & $=$ & - & - & $=$ & $z$ & 2 & -32.3 & $\frac{x 11}{834}$ & $\frac{160}{32 n}$ & $=$ & $\begin{array}{l}148 \\
-\quad 76.5 \\
\end{array}$ \\
\hline 290 & 76 & $Q B$ & - & - & - & $=$ & - & - & - & - & - & - & 133 & 323 & - & -148 \\
\hline Treal & 22999 & 0.5 & 1083 & 28 & 9903 & 0.4 & 469 & 1.5 & $39 \$ 81$ & 6.3 & 669 & 58 & 7455 & 17.4 & 2645 & 1.47 .3 \\
\hline
\end{tabular}

The variations across studies can be ascribed in part to differences in selection bias, which are difficult to characterize, and in part to the number of risk factors on which the estimates are based, which varies across cohorts but is easy to determine (Table 6 and Table 7). In each cohort, the prevalence of women with at least one risk factor increased with age, although the magnitude of this increase varied across cohorts, being greatest and statistically significant in E3N, MONICA, PAQUID, and OFELY. In EPIDOS, the increase was not statistically significant. A difference was found between the 90-year or older group and the other age groups within this study.

The prevalence of women older than 50 years of age who had at least two risk factors, as determined from eight studies (Table 7) ranged from 0.4\% in MONICA to 17.4\% in EPIDOS. In most studies, the prevalence of women with at least two risk factors was far smaller than the prevalence with at least one risk factor. In the EPIDOS study, which investigated five risk factors (menopause before 40 years of age, BMI lower than $19 \mathrm{~kg} / \mathrm{m}^{2}$, history of fracture, history of hip fracture in the mother, and history of glucocorticoid therapy), $51.1 \%$ of the women aged $75-79$ years had at least two risk factors, as compared to only $13.3 \%$ in the PAQUID study, which collected only two risk factors (menopause before 40 years of age and BMI $<19$ $\mathrm{kg} / \mathrm{m}^{2}$ ). However, there was clearly a cohort effect, as the prevalences in matching age groups were very different in the EVA study, which also collected only the same two risk factors.

\section{Number of women at risk for osteoporosis in France}

We estimated the number of women at risk for osteoporosis based on the prevalences of women with at least one or two risk factors and on the 1999 French census data (INSEE). The crude and standardized results are reported for each risk factor (Table 8) and according to the number of risk factors (Table 9).

Table 9. Estimated number of women with at least one or at least two risk factors for osteoporosis

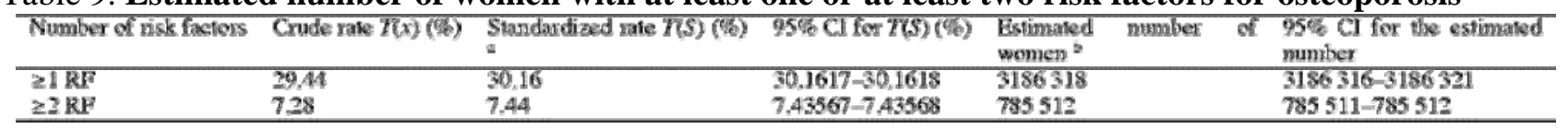

95\% CI, 95\% confidence interval; RF, risk factor.

About 1.5 million postmenopausal women in France had their menopause before 40 years of age and may, therefore, be at risk for osteoporosis (Table 8). Nearly 700000 women older than 50 years may have a BMI smaller than $19 \mathrm{~kg} / \mathrm{m}^{2}$, over 2 million a history of fracture, over 1 million a history of proximal femoral fracture in their mother, and slightly less than 612000 a history of glucocorticoid therapy. Our estimate of about 400000 women older than 50 years with a history of disorders potentially responsible for osteoporosis should be viewed with caution. Overall, we estimate that 3186318 (30\%) women older than 50 years living in France may have at least one risk factor for osteoporosis (Table 9). The prevalence of women with at least two risk factors may be far lower, from $0.4 \%$ in the MONICA cohort to $8.8 \%$ in the OFELY cohort ( Table 7). Overall, we estimate that, in France, about 785512 (7.4\%) women older than 50 years have at least two risk factors for osteoporosis ( Table 9). 


\section{Discussion}

The sample sizes used for our prevalence computations ranged from only 4321 for disorders potentially responsible for osteoporosis to 51179 for a BMI lower than $19 \mathrm{~kg} / \mathrm{m}^{2}$. Mean prevalences calculated from our samples were $15 \%$ for early menopause, $7.5 \%$ for BMI; $17.6 \%$ for a history of fracture, $8.8 \%$ for a history of proximal femoral fracture in the mother, $4.3 \%$ for a history of disorders potentially responsible for osteoporosis, and $6.6 \%$ for a history of long-term glucocorticoid therapy.

We based our choice of risk factors on the ANAES recommendations, which are fairly general, similar to other recommendations. For instance, they do not consider age, although the impact of risk factors varies with age. Thus, from a clinical viewpoint, menopause before 40 years of age has a far greater impact in younger women than in older women. Conversely, a history of proximal femoral fracture in the mother seems to have a greater impact at 70 than at 50 years of age.

The sample of women older than 50 years used for our study was obtained from a heterogeneous source and was not representative of the population living in France. We obtained information from nine cohorts totaling 123986 women. The cohort studies differed in terms of their objectives, recruitment method, sampling method, selection criteria, and geographic location. In addition, there were differences in the methods used to collect data on risk factors. Not all the studies obtained information on all the risk factors used in our study. In addition, differences in risk factor definitions occurred across studies.

Although the ANAES recommendations apply to postmenopausal women, we studied women older than 50 years of age. This change was necessary to derive reasonable estimates from demographic data, which include age but not hormonal status. It may have introduced a small degree of overestimation, as a small proportion of women older than 50 years of age are premenopausal.

When each risk factor is analyzed separately using the pooled data from all the cohorts, the results suggest an age effect (last column in Table 2). The prevalence of early menopause seems to increase from $13 \%$ in the $50-54$-year group to $31 \%$ in the 90 -year or older group. However, the $65-69,70-74$, and 90 year or older groups comprised small numbers of women (662, 525, and 133, respectively). These small sample sizes exacerbate the effect of sampling variations. The results in these three groups differ noticeably from those in the other age groups: prevalences were lower in the 65-69 and 70-74-year groups than in the younger groups and substantially higher in the 90 -year and older group than in the younger groups. This complicates the interpretation of the results. A cohort effect occurred, as shown clearly in Table 2. In the PAQUID study, for instance, the prevalence of early menopause was considerably lower than in the other five cohorts, including the two that investigated similar age groups. For the 65-69 and 70-74-year groups, the data came from only two studies; in addition, one of these studies (PAQUID) supplied $80-91 \%$ of the sample. Thus, Table 2 shows greater variability across cohorts than across age groups within each cohort. Nevertheless, because we had no objective data indicating which cohort was the most representative, we computed the final estimations on the total sample obtained by pooling the nine cohort studies.

Regarding low BMI, the E3N cohort provided more than half the sample (34 851/51 179 women) used to calculate the mean prevalence $(7.5 \%)$ for the seven cohorts. The prevalence standardized for the population in France was estimated at 6.6\% (6.5-6.7\%). No major age-related variations occurred within each cohort (Table 3).

The prevalence of a history of fracture was highest in the EPIDOS cohort (37.1\%). This cohort was composed only of women older than 75 years of age, and identification of risk factors for osteoporosis was the main objective of the study, suggesting that the prevalence may have been higher than in the general population. In the ESTEV95 study, only peripheral fractures were taken into account, whereas the other studies also recorded vertebral fractures. This may have contributed to the low prevalence in the ESTEV95 study. After standardization, the mean prevalence was 19\% (18.5-19.4\%) (Table 8). As with early menopause, the prevalences in the 65-69 and 70-74-year groups were based on small numbers of women (61 and 89, respectively) and were considerably lower than in the other studies ( Table 2).

Finally, for all the risk factors except a history of fracture, differences across cohorts were greater than differences across age groups. In addition, because age often varied widely across cohorts (e.g. older than 75 years in EPIDOS and younger than 65 years in E3N), the age effect cannot be separated from the cohort effect. Moreover, sample sizes were small for the 65-69 and 70-74-year groups.

The data on the disorders potentially responsible for osteoporosis listed in the ANAES recommendations did not allow a reliable evaluation of this factor.

After analyzing the prevalence of each risk factor, it was important to evaluate the subset of women with more than one risk factor. Therefore, we estimated the overall prevalence of women at risk for 
osteoporosis according to the number and type of risk factors. The prevalence of women with at least one risk factor varied from $12.7 \%$ in the PAQUIS study to $30.9 \%$ in the EVA study (Table 5). In most cohorts, the prevalence of women with at least one risk factor increased from one age group to the next ( Table 6). Considerable variation was noted across studies for identical age groups. In women older than 80 years, similar discrepancies were found between the two cohorts of older women (PAQUID and EPIDOS). In the cohort composed of women living in Dordogne and Gironde, the prevalence of women with at least one risk factor was substantially lower than in the other cohorts. However, this finding cannot be construed as evidence of geographic differences, since the population in each cohort may not have been representative of the female population in the region.

Whereas $30.16 \%$ of women older than 50 years had at least one risk factor, only $7.44 \%$ had at least two risk factors. This prevalence was markedly influenced by the 65-69 and 70-74-year age groups, which had small numbers of women. Data on these two age groups came from the PAQUID and EVA studies, which investigated only two risk factors, and from the OFELY study, which recorded five risk factors but had a very small sample size. For instance, the 65-69-year group in the OFELY study contributed only 8\% of the total number of women in this age group. The cohort effect should be considering when interpreting the results. However, there was no age effect.

Thus, our results provide a reasonable estimate of the prevalence of the risk factors for osteoporosis identified by the ANAES and therefore of the number of women at risk for osteoporosis in France, based on a nonrepresentative sample of over 50000 women older than 50 years. The significant differences across cohorts evidenced in our study are a reminder that estimates are influenced by recruitment bias and sampling fluctuations. However, even a study in a representative sample would provide only a rough estimate of the number of women likely to undergo absorptiometry, since this number depends not only on the presence of risk factors but also on the behavior of women regarding their health and on the prevalence of hormone replacement therapy among postmenopausal women.

\section{Acknowledgements}

We are grateful to the coordinators of the nine cohort studies and to the national health insurance for providing us with the data needed for this study: for E3N, the study coordinator Françoise Clavel-Chapelon and the statistician Valérie Avenel; for EPIDOS, the study coordinators Gérard Bréart and Pierre Meunier; for ESTEV, the research unit director Denis Hemon and the study coordinator Francis Derriennic; for EVA, the research unit director Annick Alperovitch and the study coordinator Claudine Berr; for GAZEL, the research unit director Marcel Goldberg; for MONICA, the research unit director Pierre Ducimetière; for OFELY, the research unit director Pierre Dominique Delmas; for PAQUID, the research unit director Roger Salamon and the study coordinator Jean-François Dartigues; for POLA, the research unit director Laure Papoz and the study coordinator Cécile Delcourt; and for the national health insurance data, the head physician Pierre Vermorel and the statistician Valérie Tainturier. This study was funded by the National Health Agency (Direction Générale de la Santé).

\section{References}

1. M. Espallargues, L. Sampietro-Colomb, M.D. Estrada, M. Sola, L. Del Rio, J. Setoain et al., Identifying bone-mass-related risk factors for fracture to guide bone densitometry measurements: a systematic review of the literature. Osteoporosis Int 12 (2001), pp. 811-822.

2. A.M. Tromp, M.E. Ooms, C. Popp-Snijders, J.C. Roos and P. Lips, Predictors of fractures in elderly women. Osteoporosis Int 11 (2000), pp. 134-140.

3. S.R. Cummings, M.C. Nevitt, W.S. Browner, K. Stone, K.M. Fox, K.E. Ensrud et al., Risk factors for hip fracture in white women. New Engl J Med 332 (1995), pp. 767-773.

4. C.E. De Laet, B.A. van Hout, H. Burger, A. Hofman and H.A. Pols, Bone density and risk of hip fracture in men and women: cross sectional analysis. Br Med J 315 (1997), pp. 221-225.

5. Agence Nationale d'Accréditation et d'Evaluation en Santé, Les indications des mesures quantitatives du tissu osseux: actualisation. , ANAES, Paris (2000).

6. J.A. Kanis, J.P. Devogelaer and C. Gennari, Practical guide for the use of bone mineral measurements in the assessment of treatment of osteoporosis: a position paper of the European Foundation for Osteoporosis and Bone Disease. Osteoporosis Int 6 (1996), pp. 256-261.

7. J.A. Kanis, P. Delmas, P. Burckhardt, C. Cooper and D. Torgeson, Guidelines for diagnosis and management of osteoporosis. Osteoporosis Int 7 (1997), pp. 390-406.

8. H.K. Genant, C. Cooper, G. Poor, I. Reid, G. Ehrlich, J. Kanis et al., Interim report and recommendation of the World Health Organization task force for osteoporosis. Osteoporosis Int 10 (1999), pp. 259-264.

9. Catalan Agency for Health Technology Assessment, Guidelines for the indication of bone densitometry in the assessment of fracture risk. , CAHTA, Barcelona (1999). 
10. National Osteoporosis Foundation, Physician's guide to prevention and treatment of osteoporosis. , DC: NOF, Washington (1998).

11. National Institutes of Health, NIH Consensus Development Conference on osteoporosis prevention diagnosis and therapy, March 27-29, 2000. , MD: NIH, Bethesda (2000).

12. National Institutes of Health, Osteoporosis prevention, diagnosis and therapy. J Am Med Assoc 258 (2001), pp. 785-795 Consensus Development Conference, March 27-29, 2000 .

13. American Association of Clinical Endocrinologists, AACE clinical practice guidelines for the prevention and treatment of postmenopausal osteoporosis. , FL: AACE, Jacksonville (1996).

14. L’ostéoporose chez les femmes ménopausées et chez les sujets traités par corticoïdes: méthodes diagnostiques et indications. Agence Nationale d'Accréditation et d'Evaluation en Santé/Service recommandations et références professionnelles/avril; 2001.

15. F. Clavel-Chapelon, C. Jadand, H. Goulard and C. Guibout-Peigne, E3N a cohort study on cancer risk factors in MGEN women. Description of protocol, main characteristics population. Bull Cancer 8 (1996), pp. 10081013.

16. A.M. Schott, C. Cormier, F. Favier, E. Hausberr, P. Dargent-Molina, P.D. Delmas et al., How hip and wholebody bone mineral density predict hip fracture in elderly women: the EPIDOS Prospective Study. Osteoporosis Int 8 (1998), pp. 247-254.

17. F. Derriennic, A. Touranchet and S. Volkoff, Editors, Age-Travail-Santé. Etudes sur les salariés âgés de 37 à 52 ans, Enquête ESTEV 1990, Editions INSERM, Paris (1996) Questions en Santé Publique .

18. V. Gourlet, M.H. Verdier-Taillefer and C. Berr, Traitement hormonal substitutif chez les femmes de plus de 60 ans (cohorte EVA): analyse descriptive et étude des relations avec le fonctionnement cognitif. Année Gérontologique (2000), pp. 174-186.

19. V. Ringa, B. Ledesert and G. Breart, Determinants of replacement therapy among postmenopausal women enrolled in the French GAZEL cohort. Osteoporosis Int 4 (1994), pp. 16-20.

20. V. Lascaux-Lefebvre, J. Ruidavets, P. Arveiler, P. Amouyel, B. Haas, D. Cottel et al., Influence of parental history of hypertension on blood pressure. Hum Hypertens 13 (1992), pp. 631-636.

21. M.E. Arlot, E. Sornay-Rendu, P. Garnero, B. Vey-Marty and P.J. Demas, Apparent pre-postmenopausal bone loss evaluated by DXA at different skeletal sites in women: the OFELY cohort. J Bone Miner Res 12 (1997), pp. 683-690.

22. J.F. Dartigues, M. Gagnon, P. Barbeger-Gateau, L. Letenneur, D. Commenges, C. Sauvel et al., The PAQUID Epidemiological Program on brain aging. Neuroepidemiology 11 Suppl 1 (1992), pp. 14-18.

23. C. Delcourt, J.L. Diaz, A. Ponton-SanchezPola Study Group and L. Papoz, Smoking and age-related macular degeneration: the POLA Study. Arch Ophthalmol 116 (1998), pp. 1031-1035.

\section{Appendix A}

The cohorts identified for this study are listed below.

(1) E3N, Etude Epidémiologique de femmes de la MGEN, Unité INSERM XR 521, Institut Gustave Roussy, 94805 Villejuif cedex, France; study coordinator Françoise Clavel-Chapelon.

(2) Effets sur la santé de l'exposition aux sous-produits de l'eau,* INSERM U 420, School of Medicine, 54505 Vandoeuvre Les Nancy, France; Department head Jean-Marie Mur, study coordinator Rachel Nadif.

(3) EPIDOS, INSERM U 403, Edouard Herriot Teaching Hospital, Pavillion F, 69003 Lyon, France. Study coordinators Gérard Breart and Pierre Meunier.

(4) ESPRIT,* INSERM U 9930, Crlc Val d'Aurelle, 34298 Montpellier cedex, France; research unit director, Karen Ritchie.

(5) ESTEV, évolution des déficiences en fonction de l’âge et des caractéristiques physiques et organisationnelles de cours au la vie active, INSERM U 170, 94807 Villejuif cedex, France; research unit director Denis Hemon, study coordinator Francis Deffiennic.

(6) EVA, étude des three cites, INSERM U 360, GH Pitie-Salepetriere, 75651 Paris cedex 13, research unit director Annick Alperovitch, study coordinator Claudine Berr.

(7) GAPIC*, INSERM U 525 (Génétique épidémiologique et moléculaire des pathologies cardiovasculaires) PitiéSalpêtrière School of Medicine, 75634 Paris cedex 13, research unit director François Cambien, study coordinator S. Blankenberg.

(8) Cohorte Gazel, INSERM U 88, St. Maurice National Hospital, 94415 St. Maurice cedex, France; research unit head Marcel Goldberg.

(9) “Les femmes dans la ville”: épidémiologie en santé périnatale \& santé des femmes, INSERM U149, Tenon Teaching Hospital, 75970 Paris cedex 20, France; research unit director Gérard Breart.

(10) Mastopathies bénignes et risque de cancer du sein ${ }^{* \circ}$, INSERM U 521, Institut Gustave Roussy, 94805 Villejuif cedex, France; research unit director Catherine Bonaiti, study coordinator Monique LE.

(11) MONICA, INSERM U 258, Paul Brousse Teaching Hospital, 94807 Villejuif cedex, France; research unit director Pierre Ducimetiere.

\footnotetext{
This study was not included.
} 
(12) OFELY, INSERM U 403, Edouard Herriot Teaching Hospital, Pavillion F, 69003 Lyon, France; research unit director Pierre Dominique Delmas.

(13) PAQUID, INSERM U 330, Victor Segalen University, 33076 Bordeaux cedex, France; research unit director Roger Salamon, study coordinator Jean-François Dartigues.

(14) POLA, INSERM U 500, 34093 Montpellier cedex 05, France; research unit director Laure Papoz, study coordinator Cécile Delcourt.

(15) Etude SU VI MAX (SUpplémentation en VItamines et Minéraux AntioXydants), Institut Scientifique et Technique de la Nutrition et de l’Alimentation, 75003 Paris, Investigateur principal Serge Hercberg.

(16) Health Insurance Database, regional National Health Insurance Agencye, 69436 Lyon cedex 03, France; Head physician Pierre Vermorel, statistician Valérie Tainturier. 